\title{
BMJ Open Study protocol for investigating the impact of community home modification services on hospital utilisation for fall injuries: a controlled longitudinal study using data linkage
}

Joe Hollinghurst, ${ }^{1}$ Ashley Akbari, ${ }^{1,2}$ Richard Fry, ${ }^{1,3}$ Alan Watkins, ${ }^{1}$ Damon Berridge, ${ }^{1}$ Andy Clegg, ${ }^{4}$ Sarah Hillcoat-Nalletamby, ${ }^{5}$ Neil Williams, ${ }^{6}$ Ronan Lyons, ${ }^{1}$ Amy Mizen, ${ }^{1}$ Angharad Walters, ${ }^{1}$ Rhodri Johnson, ${ }^{1}$ Sarah Rodgers ${ }^{1,7}$

To cite: Hollinghurst J, Akbari A, Fry $\mathrm{R}$, et al. Study protocol for investigating the impact of community home modification services on hospital utilisation for fall injuries: a controlled longitudinal study using data linkage. BMJ Open 2018;8:e026290. doi:10.1136/ bmjopen-2018-026290

- Prepublication history and additional material for this paper are available online. To view these files, please visit the journal online (http://dx.doi. org/10.1136/bmjopen-2018026290).

Received 28 August 2018 Revised 18 September 2018 Accepted 28 September 2018

Check for updates

(C) Author(s) (or their employer(s)) 2018. Re-use permitted under CC BY-NC. No commercial re-use. See rights and permissions. Published by BMJ.

For numbered affiliations see end of article.

Correspondence to

Professor Sarah Rodgers;

Sarah.Rodgers@liverpool.ac.uk

\section{ABSTRACT}

Introduction This study will evaluate the effectiveness of home adaptations, both in preventing hospital admissions due to falls for older people, and improving timely discharge. Results will provide evidence for services at the interface between health and social care, informing policies seeking to promote healthy ageing through prudent healthcare and fall prevention.

Methods and analysis All individuals living in Wales, UK, aged 60 years and over, will be included in the study using anonymised linked data from the Secure Anonymised Information Linkage Databank. We will use a national database of home modifications implemented by the charity organisation Care \& Repair Cymru (C\&R) from 2009 to 2017 to define an intervention cohort. We will use the electronic Frailty Index to assign individual levels of frailty (fit, mild, moderate or severe) and use these to create a comparator group (non-C\&R) of people who have not received a C\&R intervention. Coprimary outcomes will be quarterly numbers of emergency hospital admissions attributed to falls at home, and the associated length of stay. Secondary outcomes include the time in moving to a care home following a fall, and the indicative financial costs of care for individuals who had a fall. We will use appropriate multilevel generalised linear models to analyse the number of hospital admissions related to falls. We will use Cox proportional hazard models to compare the length of stay for fall-related hospital admissions and the time in moving to a care home between the C\&R and non-C\&R cohorts. We will assess the impact per frailty group, correct for population migration and adjust for confounding variables. Indicative costs will be calculated using financial codes for individual-level hospital stays. Results will provide evidence for services at the interface between health and social care, informing policies seeking to promote healthy ageing through prudent healthcare and prevention.

Ethics and dissemination Information governance requirements for the use of record-linked data have been approved and only anonymised data will be used in our analysis. Our results will be submitted for publication in peer-reviewed journals. We will also work with lay members and the knowledge transfer team at Swansea University to create communication and dissemination materials on key findings.
Strengths and limitations of this study

- This study is a national retrospective controlled evaluation of a non-randomised intervention using data on fall prevention home modifications and fall admissions for individuals linked at individual and household levels, analysed in a safe haven with social and health-based confounding factors.

- This study is sufficiently powered to detect an effect of the Care \& Repair Cymru fall prevention home modifications on fall-related hospital admissions, having access to primary care general practice records for the majority of people nationally in Wales, UK and a nationally recorded intervention.

- Using anonymised data in a safe haven linked at individual and residential levels will allow analysis of the intervention effect on when individuals move from private residences to care homes.

- Intervention data from 2009 to 2017 contribute to a longitudinal study distinguishing between pre-intervention and postintervention at an individual level, including a similarly frail national comparator group.

\section{INTRODUCTION}

Background

There are significant issues around the sustainability of public services internationally, ${ }^{1}$ and healthy ageing is a key factor and challenge for policy makers, planners, commissioners and providers of services. ${ }^{2}$ Government policies seek to promote healthy ageing through prudent healthcare and fall prevention. ${ }^{3} 4$ This study will evaluate the effectiveness of home adaptations, both as an approach to support independent living, and a measure to prevent hospital admissions due to falls for older homeowners.

As people age, they may find it more difficult to live independently in safety and comfort of their own home. Reduced mobility, perhaps 
associated with a fall, can make moving around the home more difficult. Falls at home for older people result in high morbidity, earlier mortality ${ }^{5}$ and health inequalities. ${ }^{6}$ In particular, falls are reportedly the leading cause of deaths and hospital admissions due to injury in Wales. ${ }^{7}$

People will ideally stay well and live at home in their community. For those who need to go to hospital, once treatment is complete, it is better to minimise delays to their discharge. Delayed discharges are potentially harmful to older people because of the negative impact on their overall psychological and physical well-being, with particular concern regarding the rapid loss of muscle mass and strength that can accompany an extended hospital stay. ${ }^{8}$ Additionally, there is an association between delayed discharge and earlier mortality, infections, depression and a reduction in patients' mobility and their daily activities. ${ }^{9}{ }^{10}$ Delayed discharges are also recognised to cause considerable hospital bed pressures and an increased cost for health services. ${ }^{11}$

Previous research on the rate ratios of hospital admissions relating to falls (adjusted relative risk (RR) 1.10, 95\% CI 1.01 to 1.19) and hip fractures (adjusted RR $1.05,95 \%$ CI 0.95 to 1.16 ) indicates small and inconclusive evidence of a link between socioeconomic status and falls. ${ }^{12}$ Generally, the evidence base for large-scale environmental interventions is scarce with only 28 published studies completed prior to $2011 .^{13}$ A systematic review of fall prevention recognised limitations including a lack of control group and potential bias with respect to sequence generation, allocation generation, blinding, incomplete outcome data and selective outcome reporting. ${ }^{14}$

Falls prevention as a strategic development in local communities is a national priority in England and Wales ${ }^{1516}$ and an opportunity exists to develop generalisable evidence based on electronic records gathered over more than a decade. Systematic review conclusions suggest a lack of statistically powerful evidence. ${ }^{7}$ Larger studies with sufficient sample sizes could provide the necessary statistical power to demonstrate significant intervention effects. Use of routine data provides a sufficiently large sample size to fulfil these needs.

Routine data often have minimum coded information and therefore larger studies are at the expense of rich clinical detail. We will have public and patient involvement consisting of patients, their carers and stakeholder groups. This will add context and highlight potential mechanisms for falls and delayed discharge and will help us to interpret our results. Our results may indicate areas for further qualitative study.

A systematic review in 2013 found that intervention evaluations benefited vulnerable people the most, but the results were unclear, potentially due to aggregation at area level, rather than individual level. ${ }^{17}$ Since then, a cluster randomised controlled trial in New Zealand for 900 people receiving state benefits found a $26 \%$ reduction in injury rate caused by falls at home (derived using administrative data) for people exposed to the intervention compared with the control group. ${ }^{18}$ Furthermore, those injuries specific to the home-modification were reduced by $39 \%$. The authors suggested testing the effectiveness of particular interventions.

Although fall and injury prevention research is relatively common, large-scale intervention studies tend to be advice or medication based, ${ }^{14}{ }^{19}$ while some studies suggest emphasis should move from treatment to fall prevention. ${ }^{20}$ The majority of research including home interventions investigates them as part of a multicomponent intervention, and research solely investigating home interventions is relatively uncommon. ${ }^{21}$ This is despite home interventions enhancing the quality and suitability of the home environment and potentially reducing the likelihood of falls.

\section{Rationale}

Care \& Repair Cymru (C\&R) provide home interventions (eg, grab rails, stair rails) so that a person can remain in their own home and stay healthy. C\&R is a registered charity, partially funded by Welsh Government. In 2017, C\&R received over £1 million in funds, of which over $50 \%$ was used to help their clients with interventions, with the rest providing operational and fund-raising costs. ${ }^{22}$ This study will explore the impact of these C\&R interventions on the health of older people (aged 60 years and over) in terms of emergency admissions to hospital attributed to falls. We will quantify and compare the risk of delayed discharge from hospital between the intervention and comparator groups. We will investigate if individuals are able to return home to live independently in the community, or if the C\&R service avoids or postpones the need to move to residential or nursing home care.

Our intervention cohort will consist of only those people living in homes that have received the intervention. We will do this using advice and home modification data collected by C\&R that will be anonymised and linked to health data. A similar approach has previously been used successfully within the National Institute for Health Research housing regeneration and health study, where we found health utilisation reductions as a result of a whole home intervention. ${ }^{23-25}$

As we are performing an observational study, we do not have a randomised control group; instead, we will use data linkage to create a frailty-based comparator group comprising people who have not received the C\&R intervention. Data linkage avoids inherent biases by including everyone in long-term follow-up periods, with the flexibility to censor for death and migration. ${ }^{26}$

Systematic reviews suggest interventions are effective but evidence from individual studies is generally based on small sample sizes, ${ }^{27}{ }^{28}$ and it is claimed that there is weak evidence to support effectiveness of home interventions. ${ }^{27}$ Two studies currently in progress have predefined follow-up periods of 18 months and 16-20 weeks, respectively. ${ }^{29}$ In contrast, our study will be based on a large sample size ( $>400000$ individuals) and extended follow-up periods of up to 8 years. 
International organisations have committed to support the creation of healthy places to grow up and grow older. ${ }^{6} 3132$ A Welsh Government report on housing an ageing population, stated the importance of public-funded support for housing adaptations as a way of enhancing housing choices for older people. ${ }^{33}$ Our results will evidence the creation of healthy places by investigating the impact of fall-related home modifications on health utilisation. This study intends to contribute evidence to complement previous studies and reviews. ${ }^{13} 14$

Government healthcare reports support the C\&R framework of preventative measures ${ }^{34}$ but recognise challenges to secure long-term funds. In particular, without highquality supporting evidence, organisations such as C\&R Cymru are vulnerable to funding cuts during periods of austerity. ${ }^{35}$ The government report also comments that robust and systematic evaluations are largely absent. The evidence indicates the need for a timely, large-scale, robust study to add to the evidence base for environmental interventions. Our evidence may protect funding to promote public health and reduce health inequalities worldwide.

\section{Aims and objectives}

Our main aim is to determine whether home modification interventions improve fall injury outcomes using a health utilisation proxy of emergency hospital admissions related to falls. To achieve our aim, we will complete the following specific objectives:

1. Create a primary care general practice data Frailty Index and corresponding frailty population dataset.

2. Establish a national C\&R dataset, for linking to other administrative and health data, detailing interventions for individuals whose homes underwent modifications from 2009 to 2017 provided by C\&R.

3. Link the C\&R intervention data to health data and Health Resource Group cost codes to create an integrated study database, and then use this to answer specific research questions.

4. Create an anonymised care home dataset for Wales to identify if C\&R interventions delay the time it takes for individuals to move to a care or nursing home.

5. To engage with third sector organisations, the public and public health agencies to inform data collection, interpretation and disseminate results of the impact of the interventions to keep people living independently in their own homes where appropriate.

Our research questions will compare the intervention cohort preintervention and postintervention, and also with a comparator group of people throughout Wales who are similarly frail but are not clients of C\&R. Specifically our research questions are:

Q1. What is the change in fall-related hospital admissions for people in each frailty category, who receive at least one fall-related intervention?

Q2. What is the hospital admissions cost impact after receiving at least one fall-related intervention?
Q3. What is the delay in moving to a residential or nursing home setting after receiving at least one fall-related intervention?

We also plan some sensitivity and subgroup analyses: these will investigate whether the level of intervention received has the same effect in different contexts; such as, geographical, health and demographic. Due to the large numbers of people held in the Secure Anonymised Information Linkage (SAIL) Databank, these analyses will allow us to investigate patterns, but, where subgroup sample sizes are small, any conclusions we draw may be tentative.

\section{METHODS AND ANALYSIS \\ Study design}

We will conduct a longitudinal record linkage study on an intervention cohort with contemporary comparators. Our intervention cohort will comprise all persons on the $\mathrm{C} \& \mathrm{R}$ register who have received at least one advice visit, with the comparator cohort comprising individuals registered at a SAIL general practice (GP) but not on the C\&R register. We will use datasets of routinely collected health data to assess health and social care impacts of this home modification intervention. We will link multiple anonymised datasets at an individual and household level using the SAIL Databank, ${ }^{36}{ }^{37}$ and investigate changes in hospital admissions for falls, and the associated length of stay. Secondary evaluations include the time taken to move to a care home following a fall, and an evaluation of the indicative costs for care.

This is a retrospective controlled quasi-experimental study. It is therefore not possible to assign individuals randomly to groups, and so a non-randomised comparator group will be used to add meaning to results. ${ }^{26}{ }^{38-40}$ We will use a frailty-based comparator group to draw out differences through time that may be confounding our analyses. By bounding the population we will ensure the validity of inferences as they pertain to members of both intervention and comparator groups, so inferences are valid for people outside the study population. ${ }^{41}$

\section{Data sources: use of record-linked datasets}

The SAIL Databank.

The SAIL Databank is managed at Swansea University. ${ }^{36}$ SAIL includes the Welsh Longitudinal General Practice (WLGP) dataset that contains primary care data, enabling us to calculate the electronic Frailty Index (eFI) for everyone in our cohort. We will use the Patient Episode Database for Wales (PEDW) and the Emergency Department Data Set for further details of hospital admissions. We will also use the Office for National Statistics mortality data, to determine which study members died during the study window and to ascertain their cause of death. We also have access to the Welsh Demographic Service (WDS) dataset, containing historical and current addresses for all individuals registered with a general practitioner. Updates of addresses are recorded, enabling 
us to calculate individual-level residency durations at each registered address; using an encrypted Anonymised Linking Field along with a corresponding Residential Anonymous Linking Field (RALF) ${ }^{42}$ we will anonymously observe when individuals move from private residences to care homes.

C\&R intervention dataset.

The C\&R dataset contains records at the individual and household level including the type of intervention and dates for when intervention work was completed.

Care home dataset.

The care home dataset is a culmination of the registry held by the Care Inspectorate Wales, with missing details completed manually. This dataset will be anonymised and each care home will be assigned a RALF. The RALF can be linked at the individual level which allows us to check who lives in a care home, and when they moved there. Further details on the care home dataset are provided in the online supplementary material.

\section{The electronic Frailty Index}

To test the impact of the interventions for similarly frail individuals, we will use a modified version of the eFI, ${ }^{4344}$ an externally validated index useful in predicting key outcomes such as mortality, unplanned hospitalisation and nursing home admission. This index, based on the internationally established cumulative deficit model, assigns to each individual a frailty score calculated from 36 variables from primary care data that include symptoms, signs, diseases, disabilities and abnormal laboratory values, collectively referred to as deficits. The eFI is the

\begin{tabular}{ll}
\hline $\begin{array}{l}\text { Table } 1 \text { List of the } 36 \text { deficits used in the electronic Frailty } \\
\text { Index }\end{array}$ \\
\hline Activity limitation & Ischaemic heart disease \\
\hline $\begin{array}{l}\text { Anaemia and haematinic } \\
\text { deficiency }\end{array}$ & $\begin{array}{l}\text { Memory and cognitive } \\
\text { problems }\end{array}$ \\
\hline Arthritis & Mobility and transfer problems \\
\hline Atrial fibrillation & Osteoporosis \\
\hline Cerebrovascular disease & Parkinsonism and tremor \\
\hline Chronic kidney disease & Peptic ulcer \\
\hline Diabetes & Peripheral vascular disease \\
\hline Dizziness & Polypharmacy \\
\hline Dyspnoea & Requirement for care \\
\hline Falls & Respiratory disease \\
\hline Foot problems & Skin ulcer \\
\hline Fragility fracture & Sleep disturbance \\
\hline Hearing impairment & Social vulnerability \\
\hline Heart failure & Thyroid disease \\
\hline Heart valve disease & Urinary incontinence \\
\hline Housebound & Urinary system disease \\
\hline Hypertension & Visual impairment \\
\hline Hypotension/syncope & Weight loss and anorexia \\
\hline
\end{tabular}

number of deficits present as an equally weighted proportion of the total possible (table 1). Thus, an individual with a single deficit would be assigned an eFI of $1 / 36$ (0.0278); another individual with nine deficits would be assigned an eFI of $9 / 36(0.25)$. The eFI score is then used to categorise individuals in the following groups: fit (eFI value of $0-0.12)$, mildly frail $(>0.12-0.24)$, moderately frail $(>0.24-0.36)$, severely frail $(>0.36)$. To avoid circularity with the primary outcome in our analysis, we will remove 'falls' as a deficit.

\section{Setting}

We will include in our study all individuals living in Wales (UK), who were registered at a GP submitting data to SAIL and aged 60 years or over in 2009. In 2016, Wales had an estimated population of 3113 150, with 819425 (26.3\%) aged 60 years or over. ${ }^{45}$ This age group coincides with the age of the majority of clients from the C\&R dataset, and the age of individuals used to develop the eFI.

\section{Participants}

\section{The intervention group}

This comprises individuals receiving $\mathrm{C} \& \mathrm{R}$ advice visits and physical interventions to reduce falls. The minimum intervention received will be an advice visit. A previous anonymised version of the C\&R interventions dataset contained records for 83162 homes and 86493 people (2009-2012). We will link an additional 5 years of data, providing at least another 40000 people. We therefore anticipate that we will have data corresponding to approximately 120000 people and 110000 homes. After implementing the age restriction and linking to the GP dataset, required to calculate the eFI, we estimate that we will maintain a cohort of approximately 80000 individuals. These individuals will be compared with those who are similarly frail but have not received the intervention.

\section{The non-intervention (comparator) group}

To calculate the frailty of individuals we require longitudinal data from our GP dataset for people aged 60 and over, and who can also be linked to the WDS and PEDW databases. Under these restrictions, we have records for over 400000 people of interest; excluding individuals assigned to the intervention group thus leaves approximately 320000 individuals in our non-intervention (comparator) group.

\section{Interventions}

The interventions from C\&R are varied and can consist of advice visits and/or physical interventions to improve the home. Specifically, the C\&R database contains over 100 different types of home interventions. In keeping with the study by Keall $e t a l$, we will focus on interventions that are related to the prevention of falls and accidents, ${ }^{18}$ which is approximately half of the interventions listed. The interventions we will use, along with their frequencies from 2009 to 2012 are detailed in table 2. 
Table 2 Care \& repair interventions with counts* and percentages $†$

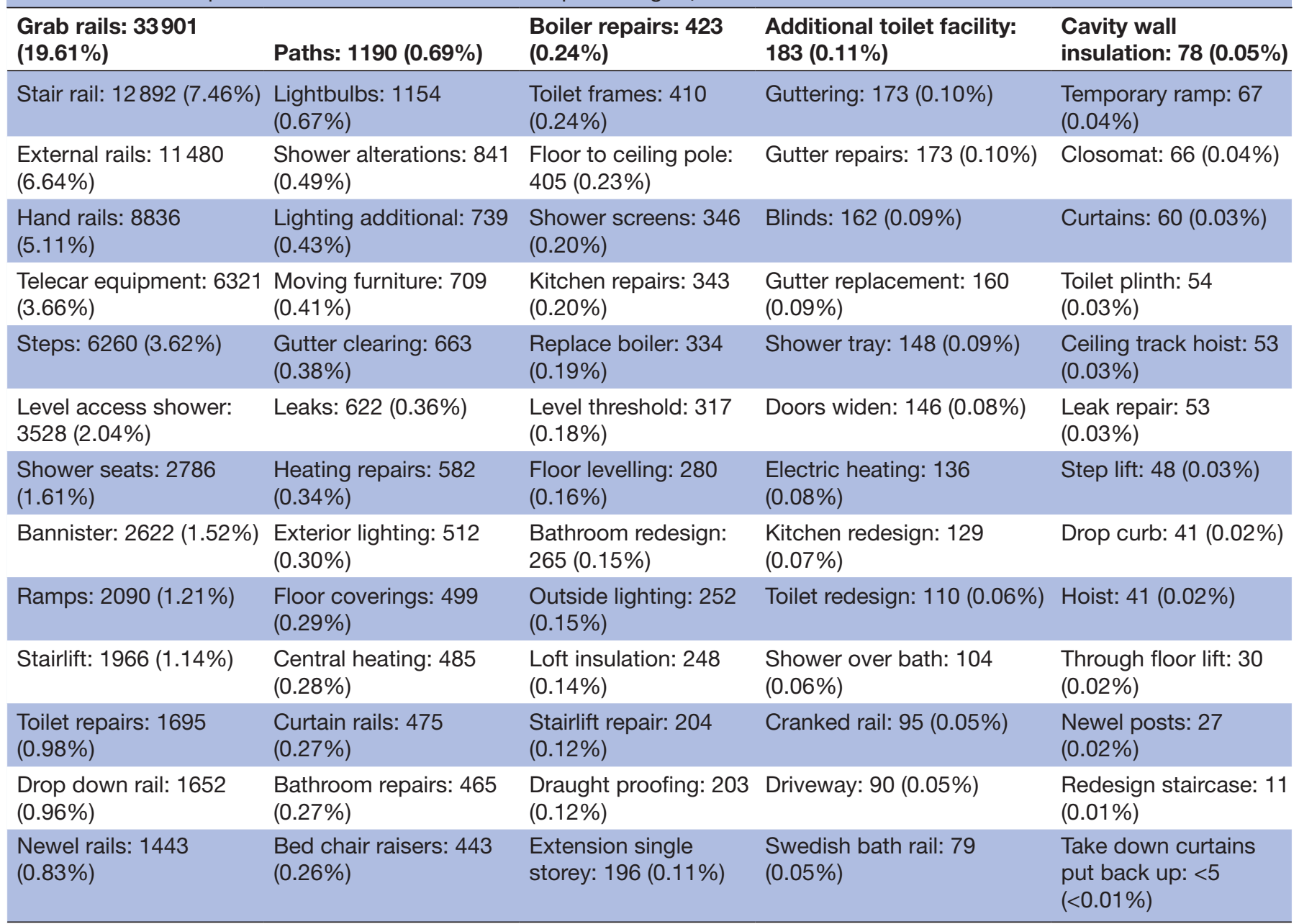

${ }^{*}$ Counts are the numbers of individuals receiving an intervention as people may receive more than one, eg, two grab rails.

†Percentages are calculated using the total of all interventions in the Care \& Repair dataset, not only the ones listed here.

We will explore how to categorise the interventions to operationalise these data for analysis. For example, it is possible to limit the analysis to:

- Assessment/advice visit only;

- One or more adaptations/interventions.

Depending on an exploration of the routine intervention data, we may categorise the interventions into types, or a combination of both methods. A suggestion by our C\&R investigators is to categorise as:

- Interventions to prevent: falls on stairs, falls on a level, falls between levels, falls in bathroom/bedroom or indirect causes for falls (such as cold homes);

- Indoor or outdoor intervention;

- Three groups of adaptation received: falls on stairs, falls on a level, falls between levels.

\section{Outcomes}

Primary outcomes

The primary outcome will be the number of fall emergency hospital admissions obtained at a quarterly resolution for the period 2009-2017 from the PEDW dataset. This coincides with the intervention dataset (2009-2017) and allows a year follow-up for those clients receiving an intervention in 2016. We will then compare the number of falls for C\&R clients with equally frail non-C\&R clients. Using a quarterly resolution will provide us with repeated measures for each individual, consisting of a discrete count of the number of relevant hospital admissions for an individual of interest. Repeated measures have many statistical benefits, and provide us with the flexibility to investigate different observation periods. ${ }^{46} 47$

Each hospital admission also has an associated length of stay and we will analyse the difference in time spent in hospital between our intervention and non-intervention groups for 5,15 and 30 days intervals which relates to a short-term, medium-term and long-term stay as mentioned by Clegg et al. ${ }^{44}$ We will analyse the length of stay due to its importance in relation to delayed discharge, and the associated problems for older people.

\section{Secondary outcomes}

We will investigate the potential risk of moving to a care home following a fall. This will be a comparison between the likelihood of a C\&R client, and an equally frail non-C\&R client remaining in their own home for 1 , 3 or 5 years following a fall-related hospital admission. 
These time periods are used in frailty-related outcomes as described by Clegg et $a$. $^{44}$

We will use Healthcare Resource Group (HRG) codes to find an indicative cost for each hospital admission. This will allow us to show the potential money saving capabilities of preventative measures.

\section{Sample size}

In this retrospective controlled quasi-experimental study, the sample size is fixed and so we can calculate the power available to detect a clinically important difference in our primary outcome of fall-related hospital admissions. A power calculation was completed based on the preintervention sample size receiving grab rails only. Using previously linked data, we found a preintervention fall rate of 0.095 per person for $\mathrm{n}=14589$, and for a minimum detectable difference of $10 \%$, and a postintervention rate of 0.085 , we can achieve a power of $80 \%$. This calculation was completed using methods similar to those by Shieh. ${ }^{48}$ They are based on functions of the probability of a single explanatory variable: whether the intervention has occurred or not. We are confident that through the update of intervention data, we will have a sufficient sample size to detect an effect with $90 \%$ power. Additionally, we only focused on grab rail installations for this calculation, and as discussed, there are several other interventions that are aimed at reducing falls, further increasing our power to detect smaller changes.

\section{Statistical methods}

Health outcomes will be evaluated over time through the construction of observation periods/event histories. The exposure periods for an individual will also be recorded, and this will be calculated using the intervention completion dates from the C\&R dataset. This will enable changes in health outcomes observed over the study period for C\&R clients to be evaluated, both against themselves for pre-intervention and postintervention, and in relation to a non-intervention and frail comparator group.

To analyse our primary outcome, the number of fall-related hospital admissions, we will create a discrete time event history dataset using a quarterly resolution. We will use a quarterly time window to ensure we have adequately precise repeated measures data, while not creating a dataset that is too large to analyse efficiently. When investigating the associated length of stay for a fall and moving to a care home, we will use a continuous time dataset.

\section{Primary outcome analysis}

For our primary outcome, we propose using the Poisson mixed model to analyse quarterly longitudinal data, modelling the mean number of fall emergency admissions, represented with discrete counts. The additional use of multiple levels will allow us to incorporate area, household and person-specific random effects, which have the ability to account for correlation in repeated measures for each individual, and allows for unbalanced data where individuals are observed for different time frames across the study window.
We will analyse the corresponding length of stay associated with a fall emergency admission using a Cox regression model as a second primary outcome. This will allow us to analyse the time a C\&R client remains in hospital following a fall compared with the matched frailty comparison group, with adjustments for confounders.

\section{Secondary outcome analysis}

Potential delays in moving to a care home will also be evaluated using a Cox regression model, analysing the time a C\&R client remains in their own home following a fall compared with the matched frailty comparison group, with adjustments for confounders. This analysis will provide us with a hazard rate, showing us the relative likelihood of moving to a care home over a set period for the non-C\&R clients compared with our intervention group, the C\&R clients.

To find the indicative cost, we will repeat our modelling of the primary outcome and simply replace the admission events with a cost derived from HRG codes for each individual hospital stay.

\section{Confounders}

Although we will use frailty categories to stratify the population for both our intervention and comparator groups, we acknowledge there may be differences remaining that are both known and unknown. We will therefore use multilevel (or mixed) models and include person level, household and area level characteristics to adjust for potential confounders, including deprivation, age and gender. By using multilevel models, we also aim to understand the magnitude of variation between individuals, households and areas. This will allow us to differentiate between the intervention effects and underlying variation between the individual, household and area. We will present results stratified by deprivation and frailty to assist with translating our results to policy, practice and the public.

\section{Initial conditions}

The first time period of intervention data assumes no prior knowledge of interventions that have taken place. This can lead to erroneous or misleading results as individuals may already have recently received unrecorded interventions. We will therefore model the first year separately to ensure we account for the initial conditions problem. ${ }^{49}$

\section{Stratification by frailty category}

We will stratify our analysis using the frailty categories: fit, mild, moderate and severe. This will ensure we are comparing similarly frail individuals. It will also allow us to evaluate which category benefits the most from fall-related interventions.

\section{Patient and public involvement}

A public panel was involved in creating this proposal. To ensure the project remains focused, we have collaborators and experts in the relevant fields, including a clinical academic geriatrician, statistical expert, social gerontologist and C\&R representatives. We will also 
involve patients, their carers and health and social care groups to help interpret the results. This will add to the evidence by providing insights into potential mechanisms and improvements to future service provision. This will help us to validate our findings to most effectively support frail people in the community, and gain insight from the potential benefits in terms of the mental health and wellbeing of the intervention group. Furthermore, our findings have the potential to evidence considerable savings by preventing fall injuries, and subsequently help people to live safer and healthier lives in their own homes.

Researchers on the proposed project will work with lay members and the knowledge transfer team at Swansea University to create communication materials about the project and its key findings. Materials will be promoted via established communication channels already used by the knowledge transfer team, providing information across health and social care services, local and national government and the third sector. Additional dissemination work will be done with (and by) C\&R, and the Welsh Government, to ensure refinement of the C\&R housing advice and intervention services. Moreover, information about the research will be readily accessible and used by the public panel that helped to develop the project, our knowledge transfer and engagement teams and the wider public. This will ensure that as many people as possible will learn about the project, and benefit from its findings.

\section{DISCUSSION}

The implications of the ageing international demographic mean that use of evidence-based preventative measures is of paramount importance to prevent adverse outcomes including falls and hospitalisation. This study has considerable potential for societal benefit by providing evidence for the advantages of preventative non-healthcare interventions. Study results will also be beneficial to older people and their carers in providing opportunities to stay at home in familiar environments as a means of enhancing overall quality of life. We have a unique opportunity to link large amounts of data from healthcare and a third-party intervention service. This will help us to assess, with sufficient statistical power, the effectiveness of preventative measures.

\section{ETHICS AND DISSEMINATION}

SAIL is exempt from needing participant consent because all data are anonymised. The SAIL Databank does not fall into the remit of the National Information Governance Board who provide section 251 (formerly section 60) exemption to use identifiable data without consent.

Along with the dissemination methods described in the public engagement section, the results of the project will be submitted for publication in peer-reviewed journals.

Author affiliations

${ }^{1}$ Health Data Research UK (HDR-UK), Swansea University, Swansea, UK
${ }^{2}$ Administrative Data Research Centre Wales, Swansea University Medical School, Swansea, UK

${ }^{3}$ National Centre for Population Health and Wellbeing Research, Swansea University Medical School, Swansea, UK

${ }^{4}$ University of Leeds (Bradford Teaching Hospital), Bradford Institute for Health Research, Bradford Royal Infirmary, Bradford, UK

${ }^{5}$ College of Human and Health Sciences, Swansea University, Swansea, UK

${ }^{6}$ Care \& Repair Cymru, Cardiff, UK

${ }^{7}$ Public Health and Policy, University of Liverpool, Liverpool, UK

Acknowledgements The authors would like to acknowledge all the data providers who make anonymised data available for research. The authors would like to thank all the members of the public for providing valuable insight that led to our research questions. The authors would also like to thank Heather Dungey from Care \& Repair for providing the intervention dataset.

Contributors SR conceived the study and is principal investigator. All authors made a substantial contribution to the design of the study, and contributed to the critical revision of the final version. JH wrote the manuscript, carried out much of the literature searches and developed the data linkage strategy with $A A, A M, A n W$, $\mathrm{RJ}$ and SR that will be used to perform the statistical analysis designed by DB and AIW. RL and AC provided clinical expertise and NW and SHN provided the social care expertise that has been instrumental in developing our research questions. AC also provided access to the eFI codes that will be implemented in the SAlL Databank by JH. RF and AM provided geographical expertise that will be used to create the Care Home dataset.

Funding Health and Care Research Wales Project: HRG-16-1325, Project ID: 1325. This work was supported by Health Data Research UK, which receives its funding from HDR UK Ltd (NIWA1) funded by the UK Medical Research Council, Engineering and Physical Sciences Research Council, Economic and Social Research Council, Department of Health and Social Care (England), Chief Scientist Office of the Scottish Government Health and Social Care Directorates, Health and Social Care Research and Development Division (Welsh Government), Public Health Agency (Northern Ireland), British Heart Foundation (BHF) and the Wellcome Trust. This study makes use of anonymised data held in the Secure Anonymised Information Linkage (SAIL) Databank.

Competing interests NW is an employee of Care \& Repair Cymru. All other authors declare that they have no competing interests.

\section{Patient consent Not required.}

Ethics approval The information governance requirements for use of the SAIL Databank in this study have been approved by the independent Information Governance Review Panel (IGRP)—project 0699; a panel of people including National Health Service Research Ethics Committee (NREC) members.

Provenance and peer review Not commissioned; peer reviewed for ethical and funding approval prior to submission.

Open access This is an open access article distributed in accordance with the Creative Commons Attribution Non Commercial (CC BY-NC 4.0) license, which permits others to distribute, remix, adapt, build upon this work non-commercially, and license their derivative works on different terms, provided the original work is properly cited, appropriate credit is given, any changes made indicated, and the use is non-commercial. See: http://creativecommons.org/licenses/by-nc/4.0/.

\section{REFERENCES}

1. Hamelmann $\mathrm{C}$, Turatto $\mathrm{F}$, Then V, et al. Social return on investment: Accounting for value in the context of implementing Health 2020 and the 2030 Agenda for Sustainable Development. Copenhagen, 2017. (Investment for Health and Development Discussion Paper).

2. World Health Organization. Global strategy and action plan on ageing and health. Geneva, 2017. (Licence: CC BY-NC-SA 3.0 IGO).

3. Drakeford M. An NHS for future generations - why we are making prudent healthcare happen [Internet]. http://www.prudenthealthcare. org.uk/ph/ (cited 4 Jul 2018).

4. Aylward M. International examples of prudent approaches to healthcare [Internet]. http://www.prudenthealthcare.org.uk/ international/ (cited 4 Jul 2018).

5. NICE, NICE clinical guideline 161. Falls: Assessment and prevention of falls in older people. Natl Inst Heal Care Excell [Internet] 2013;161:1-315. www.nice.org.uk/guidance/CG161 
6. World Health Organization. WHO Global report on falls prevention in older age. [Internet]. Community Health http://www.who.int/ageing/ publications/Falls_prevention7March.pdf.

7. Public Health Wales Observatory. Burden of Injury in Wales 2012 [Internet]. Public health wales NHS trust and the Collaboration for Accident Prevention and Injury Control (CAPIC) Swansea University [Internet]. 2012 http://www.wales.nhs.uk/sitesplus/922/news/ 24859\%0D (cited 11 Jan 2017).

8. Victor CR, Healy J, Thomas A, et al. Older patients and delayed discharge from hospital. Health Soc Care Community 2000;8:443-52.

9. Lim SC, Doshi V, Castasus B, et al. Factors causing delay in discharge of elderly patients in an acute care hospital. Ann Med Singapore 2006;35:27.

10. Styrborn K, Thorslund M. Delayed discharge of elderly hospital patients-a study of bed-blockers in a health care district in Sweden. Scand J Soc Med1993;21:272-80 https://doi.org/.

11. Rojas-García A, Turner S, Pizzo E, et al. Impact and experiences of delayed discharge: A mixed-studies systematic review. Health Expect 2018;21:41-56.

12. West J, Hippisley-Cox J, Coupland CA, et al. Do rates of hospital admission for falls and hip fracture in elderly people vary by socioeconomic status? Public Health 2004;118:576-81.

13. Turner S, Arthur G, Lyons RA, et al. Modification of the home environment for the reduction of injuries. Cochrane Database Syst Rev 2011;14.

14. Goodwin V, Jones-Hughes T, Thompson-Coon J, et al. Implementing the evidence for preventing falls among community-dwelling older people: a systematic review. J Safety Res 2011;42:443-51.

15. Wanless D, Securing Good Health for the Whole Population. Dep Heal [Internet] 2004. http://webarchive.nationalarchives.gov.uk/+/ http:/www.hm-treasury.gov.uk/media/D/3/Wanless04_summary.pdf

16. Phillips J, Stirling U, Hatton-Yeo A, et al. Our Housing Agenda: meeting the aspirations of older people in Wales [Internet]. 2017 https://gov.wales/docs/desh/publications/170213-expert-groupfinal-report-en.pdf.

17. Thomson H, Thomas S, Sellstrom E, et al. Cochrane Public Health Group. Housing improvements for health and associated socioeconomic outcomes: In. Cochrane Database of Systematic Reviews [Internet]. 2013.http://doi.wiley.com/

18. Keall MD, Pierse N, Howden-Chapman P, et al. Home modifications to reduce injuries from falls in the home injury prevention intervention (HIPI) study: a cluster-randomised controlled trial. Lancet 2015;385:231-8.

19. Gillespie LD, Robertson MC, Gillespie WJ, et al. Interventions for preventing falls in older people living in the community. Cochrane Database Syst Rev 2009;15.

20. Järvinen TL, Sievänen $\mathrm{H}$, Khan KM, et al. Shifting the focus in fracture prevention from osteoporosis to falls. BMJ 2008;336:124-6.

21. Tricco AC, Thomas SM, Veroniki AA, et al. Comparisons of interventions for preventing falls in older adults: A systematic review and meta-analysis. JAMA 2017;318:1687-99.

22. Rowlands R, Jones C. Care and Repair 2017 Annual Report [Internet]. 2017 http://www.careandrepair.org.uk/files/9815/0757/ 4981/annual_report_e.pdf (cited 4 Jul 2018).

23. Rodgers SE. Health impact, and economic value, of meeting housing quality standards: a retrospective longitudinal data linkage study. Public Health 2018.

24. Rodgers SE, Bailey R, Johnson R, et al. Emergency hospital admissions associated with a non-randomised housing intervention meeting national housing quality standards: a longitudinal data linkage study. J Epidemiol Community Health 2018;72:896-903.

25. Poortinga W, Rodgers SE, Lyons RA, et al. The health impacts of energy performance investments in low-income areas: a mixedmethods approach, 2018.

26. Lyons RA, Ford DV, Moore $\mathrm{L}$, et al. Use of data linkage to measure the population health effect of non-health-care interventions. Lancet 2014;383:1517-9.

27. Heywood F, Turner L. Better outcomes, lower costs Implications for health and social care equipment : a review of the evidence. Pensions 2007.
28. Gillespie LD, Robertson MC, Gillespie WJ, et al. Interventions for preventing falls in older people living in the community. Cochrane Database Syst Rev 2012;9:CD007146.

29. Prevention of fall injury trial [Internet]. https://www.ukctg.nihr.ac.uk/ trials/trial-details/trial-details?trialNumber=ISRCTN71002650 (cited 11 Jan 2017).

30. PreFACE study: preventing falls with ACE (angiotensin-convertingenzyme) inhibitors [Internet]. [ https://www.ukctg.nihr.ac.uk/trials/ trial-details/trial-details?trialNumber=ISRCTN58995463 (cited 27 Nov 2017).

31. Hm Government. Healthy Lives, Healthy People : Healthy Lives, Healthy People : Our strategy for public health in England [Internet]. Public Health 2010;363:100 http://www.dh.gov.uk/en/Publications andstatistics/Publications/PublicationsPolicyAndGuidance/DH_ 121941.

32. Thomas G. The strategy for older people in wales $2013-2023$ [Internet]. https://gov.wales/docs/dhss/publications/130521olderp eoplestrategyen.pdf.

33. Phillips J, Stirling U, Hatton-Yeo A, et al. Our Housing Agenda: meeting the aspirations of older people in Wales, 2017.

34. Carnes-Chichlowska S, Burholt V, Beech C, et al. A Realistic Evaluation of integrated health and social care for older people in Wales, to promote independence and wellbeing-Interim report, 2013.

35. Welsh Government to pump £170m into housing initiatives | News | Inside Housing [Internet] [Internet]. https://www.insidehousing.co. uk/home/home/welsh-government-to-pump-170m-into-housinginitiatives-37385 (cited 27 Nov 2017).

36. Lyons RA, Jones $\mathrm{KH}$, John $\mathrm{G}$, et al. The SAIL databank: linking multiple health and social care datasets. BMC Med Inform Decis Mak 2009;9:3.

37. Ford DV, Jones KH, Verplancke JP, et al. The SAIL Databank: building a national architecture for e-health research and evaluation. $B M C$ Health Serv Res 2009;9:157.

38. Craig P, Cooper C, Gunnell D, et al. Using natural experiments to evaluate population health interventions: new Medical Research Council guidance. J Epidemiol Community Health 2012;66:1182-6.

39. Bonell C, Fletcher A, Morton M, et al. Realist randomised controlled trials: a new approach to evaluating complex public health interventions. Soc Sci Med 2012;75:2299-306.

40. Bonell C, Fletcher A, Morton M, et al. Methods don't make assumptions, researchers do: a response to Marchal et al. Soc Sci Med 2013;94:81-2.

41. Rothman KJ, Greenland S, Lash T. Modern Epidemiology. Third Edit: Lippincott Williams \& Williams, 2005:896.

42. Rodgers SE, Lyons RA, Dsilva R, et al. Residential Anonymous Linking Fields (RALFs): a novel information infrastructure to study the interaction between the environment and individuals' health. J Public Health 2009;31:582-8.

43. Clegg A, Young J, lliffe S, et al. Frailty in elderly people. Lancet 2013;381:752-62.

44. Clegg A, Bates C, Young J, et al. Development and validation of an electronic frailty index using routine primary care electronic health record data. Age Ageing 2016;45:353-60.

45. Office for National Statistics. Population estimates revision tool - Office for National Statistics [Internet]. 2018 https://www.ons. gov.uk/peoplepopulationandcommunity/populationandmigration/ populationestimates/datasets/populationestimatesrevisiontool (cited 31 May 2018).

46. Louis TA, a LT. General methods for analysing repeated measures. Stat Med 1988;7(1-2):29-45 http://www.ncbi.nlm.nih.gov/pubmed/ 3281207.

47. Cnaan A, Laird NM, Slasor P. Using the general linear mixed model to analyse unbalanced repeated measures and longitudinal data. Stat Med 1997;16:2349-80.

48. Shieh G. On power and sample size calculations for Wald tests in generalized linear models. J Stat Plan Inference 2005;128:43-59.

49. Berridge DM, Crouchley R. Multivariate generalized linear mixed models using R. CRC Press 2011. 